\title{
Spectral, Structural and Characterization of Neodymiumlons Doped Zinc Oxide Nanomaterial
}

\author{
Sudha Pal ${ }^{1}$, Yogesh Kumar Sharma ${ }^{2}$, Jitendra Pal Singh ${ }^{3}$ \\ ${ }^{1}$ Department of Physics, Motiram Baburam Goverment Post Graduate College, Haldwani (Nainital), India \\ ${ }^{2}$ Hukum Singh Bora Government Degree College, Someshwar (Almora), India \\ ${ }^{3}$ Department of Physics, Sardar Bhagat Singh Government Post Graduate College, Rudrapur (U S Nagar), India
}

Email address:

dryksharma@yahoo.com (Y. K. Sharma)

To cite this article:

Sudha Pal, Yogesh Kumar Sharma, Jitendra Pal Singh. Spectral, Structural and Characterization of NeodymiumIons Doped Zinc Oxide Nanomaterial. American Journal of Nanosciences. Vol. 7, No. 3, 2021, pp. 49-53. doi: 10.11648/j.ajn.20210703.11

Received: July 22, 2021; Accepted: August 26, 2021; Published: September 4, 2021

\begin{abstract}
Zinc oxide with neodymium ions nanomaterials were synthesized by using the chemical synthesis method. The materials were characterized by XRD, FTIR, TEM, SEM and spectral analysis. From XRD, TEM and SEM images, the estimated average particle size are 20,100 and $200 \mathrm{~nm}$ respectively. Nearly hexagonal shapes for the dark spots in the TEM images indicate that the $\mathrm{ZnO}$ nanoparticles are almost hexagonal. SEM demonstrates clearly the formation of cluster type of $\mathrm{ZnO}$ nanoparticles and change of the morphology of the nanoparticles with the $\mathrm{Nd}^{3+}$ different ions concentration. UV- Visible absorption spectrum of the $\mathrm{ZnO}: \mathrm{Nd}^{3+}$ nanomaterial was analyzed on the basis of Judd-Ofelt (J-O) theory. Nine absorption and four fluorescence bands have been observed at room temperature. Energy interaction and intensity parameters have been computed Fluorescence band have been assigned to transitions ${ }^{4} \mathrm{~F}_{3 / 2} \rightarrow{ }^{4} \mathrm{I}_{9 / 2},{ }^{4} \mathrm{~F}_{3 / 2} \rightarrow{ }^{4} \mathrm{I}_{11 / 2},{ }^{4} \mathrm{~F}_{3 / 2} \rightarrow{ }^{4} \mathrm{I}_{13 / 2}$, and ${ }^{4} \mathrm{~F}_{3 / 2} \rightarrow{ }^{4} \mathrm{I}_{15 / 2}$. The radiative properties were computed using the J-O intensity parameters and fluorescence data. The value of emission crosssection is an important parameter and signifies the rate of energy extraction from the optical material.
\end{abstract}

Keywords: Absorption and Fluorescence Spectrum, Judd-Ofelt (J-O) Parameters, Radiative Properties

\section{Introduction}

The rare earths are fairly abundant, but their availability is somewhat limited, primarily because their concentration levels in many ores are quite low (less than 5 percent by weight). An economically viable source should contain more than 5 percent rare earths, unless they are mined with another product [1]. $\mathrm{RE}$ doped $\mathrm{ZnO}$ nano material are those nano material in which two types of doped ions are used, one in which the outer orbital is exposed to the environment like the d-orbital in the transition metal ions and the other in which the outer orbital is shielded one, like the f-orbital in the tripositive rare earth ions. Nanosize particles of semiconductor materials have gained much more interest in recent years due to their desirable properties and applications in different areas such as catalysts [2], sensors [3], photoelectron devices [4], highly functional and effective devices [5]. These nanomaterials have novel electronic, structural, and thermal properties which are of high scientific interests in basic and applied fields [6]

The Judd-Ofelt theory [7, 8] is usually adopted to calculate transition probabilities from the data of absorption crosssections of several $f-f$ transitions. According to this theory, the strength of an $f-f$ transition may be expressed by the sum of the products of three intensity parameters $\Omega i(i=2,4,6)$ times the squared matrix elements $U(i)$ between the initial $J$ states and the terminal $J$ '-state. Once the phenomenological parameters $\Omega i$ have been calculated, it is possible to derive the strength of any absorption or emission transition, as well as the stimulated emission cross-section, the fluorescence branching ratio from level $J$ to $J^{\prime}$, and the radiative lifetime of an excited level. For understanding the luminescent properties of rare earth ions, it is necessary to know their key energy levels. The energy level may be divided into three categories, those corresponding to $4 f n$ configuration, $4 f$ $n-15 d$ configuration, and those corresponding to charge transfer involving the neighboring ions [9].

The optical studies confirm that $\mathrm{Nd}$ ion doping in $\mathrm{ZnO}$ leads to reduction in band gap and exhibits higher absorption 
in the visible region. $\mathrm{Nd}$ doping in $\mathrm{ZnO}$ films was found to have enhanced photo catalytic activity and antibacterial activity. The influence of $\mathrm{Nd}$ doping on the photo catalytic activity of $\mathrm{ZnO}$ for the degradation of methylene blue dye was studied under visible light illumination. The decrease in grain size and light absorption over an extended visible region by $\mathrm{Nd}$ ion doping in $\mathrm{ZnO}$ nanofilms contributed equally to improve the photo catalytic activity [10].

In present work an effort has been made in the synthesis of $\mathrm{Nd}^{3+}$ doped $\mathrm{ZnO}$ nanomaterials by using simple techniques based on $50-70^{\circ} \mathrm{C}$ temperature chemical synthesis method to obtain various sizes of nanoparticles. Absorption and fluorescence spectra of $\mathrm{Nd}^{3+}$ doped $\mathrm{ZnO}$ have been recorded in the visible region at room temperature. The $\mathrm{Nd}$ : $\mathrm{ZnO}$ nanomaterials have been characterized by XRD, FTIR, TEM and SEM. Judd-Ofelt, Energy interaction and radiative propertieshave computed.

\section{Experimental Method}

The $\mathrm{ZnO}: \mathrm{Nd}^{3+}$ nanomaterials prepared by chemical synthesis method [11]. $\mathrm{ZnO}: \mathrm{Nd}^{3+}$ nanoparticles have been tried in alcoholic media like ethanol, methanol or propanol. In alcoholic media growth of oxide particles is slow and convenient [12]. Different solutions have been prepared by dissolving $0.2725 \mathrm{~g}$ of $\mathrm{ZnCl}_{2}\left(10^{-1} \mathrm{M}, 20 \mathrm{ml}\right), 0.545 \mathrm{~g} \mathrm{NaOH}$ $\left(10^{-1} \mathrm{M}, 100 \mathrm{ml}\right)$ and glycerol in ethanol. Glycerol slowly added to $\mathrm{NaOH}$ solution while it has been continuously stirred.

The resulting solution has been stirred for one hour before adding $\mathrm{ZnCl}_{2}$ and $(0.2 \mathrm{~mol} \%) \mathrm{Nd}^{3+}$ ions solution to it. After two hours of constant stirring a milky white solution obtained. Size selective precipitation has been carried out using acetone as a non-solvent. The precipitate has been washed in methanol or ethanol has been allowed to evaporate at room temperature to obtain $\mathrm{ZnO}$ nanoparticles in white powder form. Similar type of method of $\mathrm{ZnO}$ with $\mathrm{Pr}^{3+}$ ion is also observed by Sharma et al for the nanopowder [13].

\section{Characterization of $\mathrm{ZnO}: \mathrm{Nd}^{3+}$ Nanomaterials}

\subsection{Structural Characterization}

$\mathrm{ZnO}$ nanomaterials with $\mathrm{Nd}^{3+}$ ionshave been characterized by XRD, SEM, TEM, FTIR to get exact information about the structure, surface morphology and particle size etc.

\subsubsection{X-Ray Diffraction (XRD)}

Sharp peaks in the XRD patterns indicate crystalline nature of the samples. XRD pattern of $\mathrm{ZnO}$ nano materials with $\mathrm{Nd}^{3+}$ ion have been shown in Figure 1. By using the DebyeScherrer equation, $\mathrm{D}=0.89 \lambda / \beta \cos \theta$, where $\mathrm{D}$ is the average crystalline size [14]. The $\mathrm{ZnO}: \mathrm{Nd}^{3+}$ nanopowder's crystalline size is estimated to be about $100-20 \mathrm{~nm}$. The peak position at 1434 and sharp diffraction bands at $2 \theta^{\circ}$ (31.730) have been observed in $\mathrm{ZnO}: \mathrm{Nd}^{3+}$ nanoparticles (Figure 1). Similar type of behavior ofLa-doped $\mathrm{ZnO}$ ion is also observed by Mai M.
A. Ahmed et al for the nano structured thin films [15].

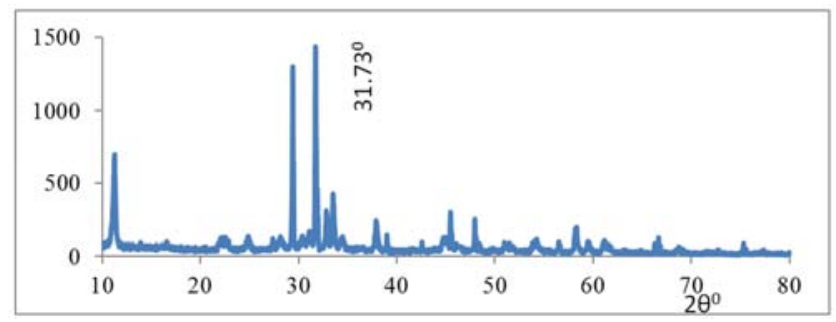

Figure 1. XRD pattern of $\mathrm{ZnO}: \mathrm{Nd}^{3+} \mathrm{ZnO}: \mathrm{Nd}^{3+}$ Nanomaterials with doping of $0.2 \mathrm{~mol} \% \mathrm{Nd}^{3+}$ ions.

\subsubsection{Scanning Electron Microscopy [SEM]}

SEM images of $\mathrm{ZnO}$ nano materials with $\mathrm{Nd}^{3+}$ have been recorded and shown in Figure 2. The image shows cluster to $\mathrm{ZnO}$ nanoparticles and the size of the particles around 200-20 $\mathrm{nm}$. It demonstrates clearly the formation of cluster type of $\mathrm{ZnO}$ nanoparticles, and change of the morphology of the nanoparticles with the $\mathrm{Nd}^{3+}$ different ions concentration. Similar type of behavior of $\mathrm{ZnO}$ : $\mathrm{Dy}^{3+}$ ( $3 \mathrm{wt} \%$ ) ion is also observed by Prathibha Vasudevan et al for the nanophosphors [16].

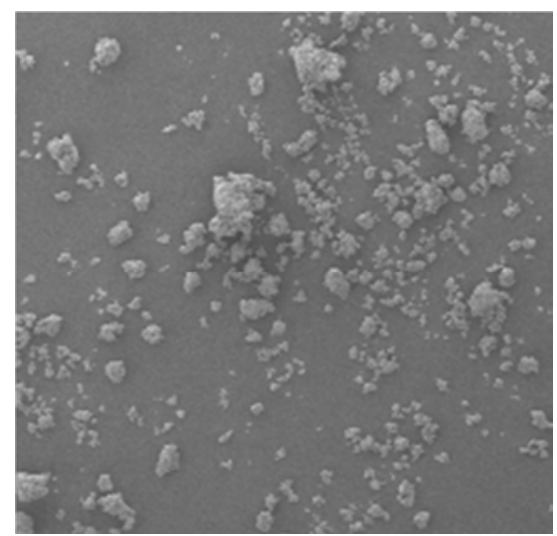

Figure 2. SEM micrograph $\mathrm{Nd}^{3+} \mathrm{ZnO}: \mathrm{Nd}^{3+}$ Nanomaterials with doping of 0.2 mol \% $\mathrm{Nd}^{3+}$ ions.

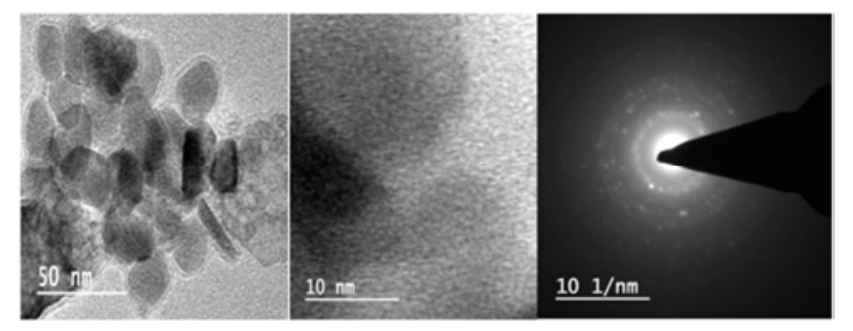

Figure 3. TEM micrograph $\mathrm{Nd}^{3+} \mathrm{ZnO}: \mathrm{Nd}^{3+}$ Nanomaterials with doping of 0.2 mol \% $\mathrm{Nd}^{3+}$ ions.

\subsubsection{Transmission Electron Microscope [TEM]}

TEM images of $\mathrm{ZnO}: \mathrm{Nd}^{3+}$ Nanomaterial have been recorded and shown in Figure 3. From figure 3, nearly hexagonal shapes for the dark spots in the images indicate that the $\mathrm{ZnO}$ nanoparticles are almost hexagonal. The estimated average particle size corresponding to $0.2 \mathrm{~mol} \%$ are $50,100 \mathrm{~nm}$. These results are also consistent with other rare earth metal ions doped like Gd-doped ZnO Nanomaterial [17]. 


\subsubsection{Fourier Transform Infrared (FT-IR) Spectra}

FT-IR spectra of $\mathrm{Nd}^{3+}$ doped Zinc Oxide Nanomaterial have been recorded and shown in Figure 4. This spectral region encompasses several important stretch modes involving hydrogen bonded to oxygen and $\mathrm{ZnO}$ and collected in Table 1. FTIR spectra of $\mathrm{Nd}^{3+}$ doped $\mathrm{ZnO}$ were recorded, employing on PC using OMNIC software. The FTIR spectra of $\mathrm{ZnO}$ nanomaterial with doping $0.2 \mathrm{~mol} \% \mathrm{Nd}^{3+}$ ions consists of several peaks which are broad and moderate in band width. Similar results are suggested by Odireleng et al [18] for $\mathrm{Eu}^{3+}$, bonds observed from the $1.0 \mathrm{~mol} \% \mathrm{Eu}^{3+}$ doped $\mathrm{ZnO}$ spectrum around 714, 1050, 1080 and $3609 \mathrm{~cm}^{-1}$ are assigned to $\mathrm{CO}_{3}{ }^{2}$ vibration mode, $\mathrm{C}-\mathrm{H}$ stretching mode and O-H group respectively [19-21].

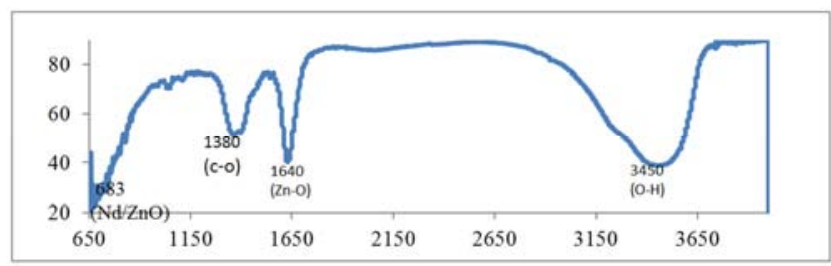

Figure 4. FTIR pattern of $\mathrm{ZnO}: \mathrm{Nd}^{3+} \mathrm{ZnO}: \mathrm{Nd}^{3+}$ Nanomaterials with doping of $0.2 \mathrm{~mol} \% \mathrm{Nd}^{3+}$ ions.

Table 1. FTIR-Observed band of $\mathrm{ZnO}: \mathrm{Nd}^{3+}$ nanoparticles with doping $0.2 \mathrm{~mol} \% \mathrm{Nd}^{3+}$ ions in Zinc Oxide.

\begin{tabular}{lll}
\hline S. No & ZnO:Nd & Assignment \\
\hline & Wave Number $\left(\mathrm{cm}^{-1}\right)$ & Bonds \\
1 & 677 & $\mathrm{Nd} / \mathrm{ZnO}$ \\
2 & 1380 & $\mathrm{C}-\mathrm{O}$ \\
3 & 1640 & $\mathrm{Zn}-\mathrm{O}$ \\
4 & 3450 & $\mathrm{O}-\mathrm{H}$ \\
\hline
\end{tabular}

\subsection{Spectral Characterization}

\subsubsection{UV-Visible Absorption Spectrum}

The absorption spectrum of $\mathrm{Nd}^{3+}$ doped $\mathrm{ZnO}$ Nanomaterial has been presented in Figure 5 in terms of wave length (nm) vs relative absorption $\left(\mathrm{I}_{\mathrm{o}} / \mathrm{I}\right)$, where $\mathrm{I}$ and $\mathrm{I}_{\mathrm{o}}$ are intensities of the radiation transmitted through specimens.

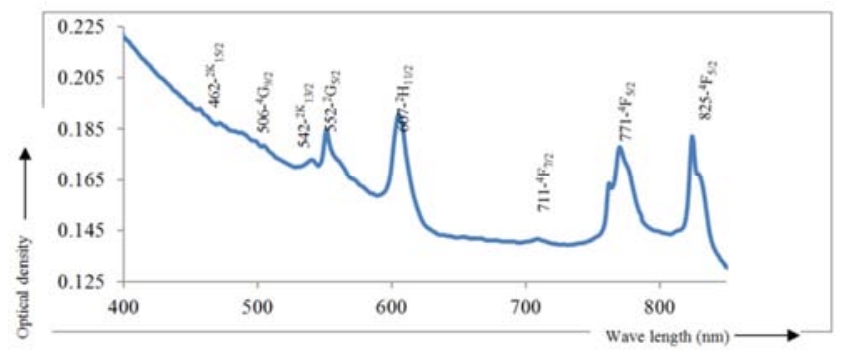

Figure 5. Absorption spectrum of $\mathrm{ZnO}: \mathrm{Nd}^{3+} \mathrm{ZnO}: \mathrm{Nd}^{3+}$ Nanomaterials with doping of $0.2 \mathrm{~mol}^{\%} \mathrm{Nd}^{3+}$ ions.

Nine absorption bands have been observed in $\mathrm{ZnO}: \mathrm{Nd}^{3+}$ $(0.2 \mathrm{~mol} \%)$ nanomaterial. The assignment of these bands from ground state ${ }^{4} \mathrm{I}_{9 / 2}$ to the excited states ${ }^{4} \mathrm{~F}_{5 / 2},{ }^{4} \mathrm{~F}_{7 / 2},{ }^{4} \mathrm{~F}_{9 / 2}$, ${ }^{2} \mathrm{H}_{11 / 2},{ }^{4} \mathrm{G}_{5 / 2},{ }^{2} \mathrm{~K}_{13 / 2},{ }^{4} \mathrm{G}_{9 / 2},{ }^{2} \mathrm{~K}_{15 / 2}$ and ${ }^{4} \mathrm{D}_{3 / 2}$ energy levels are observed and collected in Table 2. From the absorption band, Energy interaction i.e. Slater - Condon $\left(F_{k}\right)$, Racah $\left(E^{k}\right)$ and
Lande' $\left(\zeta_{4 \mathrm{f}}\right)$ parameters have been computed and collected inTable 3.

Table 2. Experimental energy $\left(E_{\text {exp }}\right)$ and Calculated energy $\left(E_{\text {cal }}\right)$ with their Differences ( $\triangle E$ ) for various absorption bands of $\mathrm{ZnO}: \mathrm{Nd}^{3+}$ (0.2mol\%) nanomaterials.

\begin{tabular}{llll}
\hline Absorption levels & $\mathbf{E}_{\text {exp }}\left(\mathbf{c m}^{-1}\right)$ & $\mathbf{E}_{\text {cal }}\left(\mathbf{c m}^{-1}\right)$ & $\Delta \mathbf{E}$ \\
\hline${ }^{4} \mathrm{~F}_{5 / 2}$ & 12953 & 12645.05 & 307.94 \\
${ }^{4} \mathrm{~F}_{7 / 2}$ & 14064 & 13649.72 & 414.283 \\
${ }^{4} \mathrm{~F}_{9 / 2}$ & 14727 & 15436.54 & -709.539 \\
${ }^{2} \mathrm{H}_{11 / 2}$ & 16447 & 16412.01 & 34.9941 \\
${ }^{4} \mathrm{G}_{5 / 2}$ & 18083 & 16837.82 & 1245.178 \\
${ }^{2} \mathrm{~K}_{13 / 2}$ & 18450 & 18879.05 & -429.044 \\
${ }^{4} \mathrm{G}_{9 / 2}$ & 19762 & 19836.7 & -74.464 \\
${ }^{2} \mathrm{~K}_{15 / 2}$ & 21786 & 21416 & 370.003 \\
${ }^{4} \mathrm{D}_{3 / 2}$ & 26385 & 27877 & -1492.299 \\
\hline
\end{tabular}

Table 3. Computed values of Slater - Condon, Lande', Racah, Nephelauxetic ratio, Bonding and Judd-Ofelt Parameters for $\mathrm{ZnO}: \mathrm{Nd}^{3+}$ (0.2mol\%) nanomaterials.

\begin{tabular}{lll}
\hline PARAMETERS & FREE IONS & ZnO: $\mathbf{N d}^{3+}(\mathbf{0 . 2} \mathbf{m o l} \%)$ \\
\hline $\mathrm{F}_{2}\left(\mathrm{~cm}^{-1}\right)$ & 331.09 & 340.86 \\
$\mathrm{~F}_{4}\left(\mathrm{~cm}^{-1}\right)$ & 50.72 & 43.22 \\
$\mathrm{~F}_{6}\left(\mathrm{~cm}^{-1}\right)$ & 5.15 & 5.72 \\
$\zeta_{4 \mathrm{~F}}\left(\mathrm{~cm}^{-1}\right)$ & 884.00 & 895.595 \\
$\mathrm{E}^{1}\left(\mathrm{~cm}^{-1}\right)$ & 5024.00 & 5033.51 \\
$\mathrm{E}^{2}\left(\mathrm{~cm}^{-1}\right)$ & 23.90 & 24.91 \\
$\mathrm{E}^{3}\left(\mathrm{~cm}^{-1}\right)$ & 497.00 & 480.85 \\
$\mathrm{~F}_{4} / \mathrm{F}_{2}$ & 0.15 & 0.12 \\
$\mathrm{~F}_{6} / \mathrm{F}_{2}$ & 0.02 & 0.01 \\
$\mathrm{E}^{1} / \mathrm{E}^{3}$ & 10.11 & 10.46 \\
$\mathrm{E}^{2} / \mathrm{E}^{3}$ & 0.05 & 0.05 \\
$\beta^{\prime}$ & --- & 0.9291 \\
$\mathrm{~b}_{1 / 2}$ & ---- & 0.02 \\
$\Omega_{2}\left(10^{-20}\right)$ & - & 3.40 \\
$\Omega_{4}\left(10^{-20}\right)$ & - & 5.67 \\
$\Omega_{6}\left(10^{-20}\right)$ & - & 4.04 \\
\hline
\end{tabular}

\subsubsection{Judd-Ofelt Intensity Parameters}

The phenomenological JO parameters have been calculated from observed line strength and collected in Table 3. These parameters show the general tendency $\Omega_{2}<\Omega_{6}<\Omega_{4}$. The $\Omega_{\lambda}$ parameters are very important since they are used in the calculation of laser parameters. $\Omega_{2}$ parameter involves the long range terms in the crystal field potential and is most sensitive to the local structural changes. The intensity of ${ }^{4} \mathrm{I}_{9 / 2} \rightarrow{ }^{4} \mathrm{G}_{5 / 2},{ }^{2} \mathrm{G}_{7 / 2}$ transition is the principal determiners of the $\Omega_{2}$. This transition satisfies the selection rule $|\Delta \mathrm{J}| \leq 2$ and is known as hypersensitive transition. A good agreement is found between the calculated and experimental line strengths. It is necessary to study the various transitions giving rise to fluorescence and compute their radiative properties utilizing the Judd-Ofelt parameters and fluorescence data. [22].

\subsubsection{Fluorescence Spectrum}

The fluorescence spectra of $\mathrm{Nd}^{3+}$ doped $\mathrm{ZnO}$ Nanomaterial have been recorded and shown in Figures 6\&7 in terms of wavelength $(\mathrm{nm})$ vs relative fluorescence in arbitrary units (a.u.). The wave length of exciting radiation is written on each spectrum. Fluorescence peak values $\left(\lambda_{\mathrm{p}}\right)$, and effective line width $\left(\Delta \lambda_{\text {eff }}\right)$ for $\mathrm{Nd}^{3+}$ doped $\mathrm{ZnO}$ nanomaterials at exciting wavelength $(\lambda)$ have been given in Table 4 . Four fluorescence 
bands have been observed in $\mathrm{ZnO}: \mathrm{Nd}^{3+}(0.2 \mathrm{~mol} \%)$ nanomaterials. They have been assigned to transitions ${ }^{4} \mathrm{~F}_{3 / 2} \rightarrow$ ${ }^{4} \mathrm{I}_{9 / 2},{ }^{4} \mathrm{~F}_{3 / 2} \rightarrow{ }^{4} \mathrm{I}_{11 / 2},{ }^{4} \mathrm{~F}_{3 / 2} \rightarrow{ }^{4} \mathrm{I}_{13 / 2}$ and ${ }^{4} \mathrm{~F}_{3 / 2} \rightarrow{ }^{4} \mathrm{I}_{15 / 2}$. The values of ' $\beta$ ' for $\mathrm{ZnO}: \mathrm{Nd}^{3+}$ has been calculated for different transitions. The results are given in Table 5. The values of ' $\beta$ ' are maximum for ${ }^{4} \mathrm{~F}_{3 / 2} \rightarrow{ }^{4} \mathrm{I}_{13 / 2}$ transition and is closely followed by ${ }^{4} \mathrm{~F}_{3 / 2} \rightarrow{ }^{4} \mathrm{I}_{9 / 2}$ for the neodymium doped $\mathrm{ZnOspecimens,} \mathrm{suggesting} \mathrm{that,} \mathrm{these}$ transitions are to be used as a laser transition. The radiative life time ' $\tau$ ' for a transition is reciprocal of spontaneous emission probability $A$. The values of ' $\tau$ ' are given in Table 5 for $\mathrm{ZnO}: \mathrm{Nd}^{3+}$ specimens. The minimum ' $\tau$ ' values have been obtained for ${ }^{4} \mathrm{~F}_{3 / 2} \rightarrow{ }^{4} \mathrm{I}_{13 / 2}$ and ${ }^{4} \mathrm{~F}_{3 / 2} \rightarrow{ }^{4} \mathrm{I}_{11 / 2}$ transitions in comparison to two others transitions [23, 24].

The stimulated emission cross-section, $\sigma_{\mathrm{p}}$ is calculated using the observed peak values of the fluorescence $\lambda_{\mathrm{p}}$, their effective line width. $\Delta \lambda_{\text {eff }}$ (Table 4) and the A values (Table 5). The $\sigma_{\mathrm{p}}$ parameter is the most important parameter. Its value (Table 5) signifies the rate of energy extraction from the laser material and is generally used to predict laser action in RE doped material prepared on laboratory scale. A large stimulated emission cross-section is of benefit for a low threshold and a high gain in laser operation.

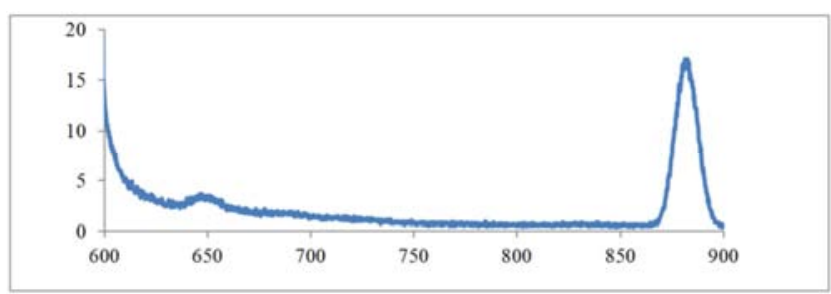

Figure 6. Fluorescence spectrum of $\mathrm{ZnO}: \mathrm{Nd}^{3+}$ Nanomaterials with doping of $0.2 \mathrm{~mol} \% \mathrm{Nd}^{3+}$ ions.

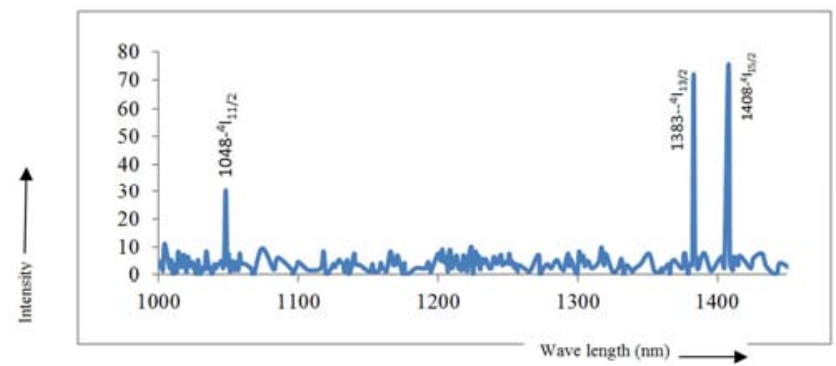

Figure 7. Fluorescence spectrum of $\mathrm{ZnO}: \mathrm{Nd}^{3+} \mathrm{ZnO}: \mathrm{Nd}^{3+}$ Nanomaterials with doping of $0.2 \mathrm{~mol} \% \mathrm{Nd}^{3+}$ ions.

Table 4. Matrix elements $\left(U^{\lambda}\right)$ [25-27] and Observed values of wavelength $(\lambda)$ and half band width $\left(\Delta \lambda_{\text {eff }}\right.$ of various fluorescence peaks for ZnO:Nd ${ }^{3+}$ $(0.2 \mathrm{~mol} \%)$ with Excitation wavelength.

\begin{tabular}{lllllll}
\hline Excitation Wavelength $\boldsymbol{\lambda}(\mathbf{n m})$ & Assignment & {$\left[\mathbf{U}^{(2)}\right]^{2}$} & {$\left[\mathbf{U}^{(4)}\right]^{2}$} & {$\left[\mathbf{U}^{(6)}\right]^{2}$} & $\boldsymbol{\Lambda}(\mathbf{n m})$ & $\Delta \boldsymbol{\Lambda}_{\text {eff }}(\mathbf{n m})$ \\
\hline \multirow{4}{*}{583} & ${ }^{4} \mathrm{~F}_{3 / 2} \rightarrow{ }^{4} \mathrm{I}_{9 / 2}$ & 0.0000 & 0.2290 & 0.0550 & 882.6 & 13.0 \\
& ${ }^{4} \mathrm{~F}_{3 / 2} \rightarrow{ }^{4} \mathrm{I}_{11 / 2}$ & 0.0000 & 0.1330 & 0.3630 & 1047.0 & 100 \\
& ${ }^{4} \mathrm{~F}_{3 / 2} \rightarrow{ }^{4} \mathrm{I}_{13 / 2}$ & 0.0000 & 0.0000 & 0.2310 & 1380.0 & 100 \\
& ${ }^{4} \mathrm{~F}_{3 / 2} \rightarrow{ }^{4} \mathrm{I}_{15 / 2}$ & 0.0000 & 0.0000 & 0.0160 & 1405.0 & 300 \\
\hline
\end{tabular}

Table 5. Spontaneous emission probability (A), Fluorescence branching ratio $(\beta)$ and Radiative time $(\tau)$ and stimulated emission cross section $\left(\sigma_{p}\right)$ for various levels of $\mathrm{ZnO}: \mathrm{Nd}^{3+}(0.2 \mathrm{~mol} \%)$ nanomaterials.

\begin{tabular}{llllll}
\hline Assignment & $\lambda(\mathbf{n m})$ & $\mathbf{A}\left(\mathbf{S e c}^{-1}\right)\left(\mathbf{1 0}^{+\mathbf{3}}\right)$ & $\boldsymbol{\beta}$ & $\boldsymbol{\tau}(\boldsymbol{\mu} \mathbf{~ s e c})$ & $\boldsymbol{\sigma}_{\mathrm{p}}\left(\mathbf{1 0}^{-\mathbf{2 0}}\right)$ \\
\hline${ }^{4} \mathrm{~F}_{3 / 2} \rightarrow{ }^{4} \mathrm{I}_{9 / 2}$ & 882.6 & 1.23 & 5.15 & 813.00 & 1.73 \\
${ }^{4} \mathrm{~F}_{3 / 2} \rightarrow \mathrm{I}_{11 / 2}$ & 1047.0 & 1.08 & 0.42 & 929.00 & 2.32 \\
${ }^{4} \mathrm{~F}_{3 / 2} \rightarrow{ }^{4} \mathrm{I}_{13 / 2}$ & 1380.0 & 0.19 & 0.09 & 509.00 & 1.28 \\
${ }^{4} \mathrm{~F}_{3 / 2} \rightarrow{ }^{4} \mathrm{I}_{15 / 2}$ & 1405.0 & 0.001 & 0.06 & 771.00 & 2.15 \\
\hline
\end{tabular}

\section{Conclusions}

$\mathrm{Nd}^{3+}$ doped $\mathrm{ZnO}$ nanomaterial have been prepared by chemical synthesis method. Structural, spectral, and morphological composition were studied after a successfully synthesis and characterized by using different techniques such XRD, SEM, TEM, FTIR, UV-VIS absorption and fluorescence spectrum. The XRD study revealed, $\mathrm{ZnO}: \mathrm{Nd}^{3+}$ nanopowder's crystalline size is estimated to be about 100-20 $\mathrm{nm}$. From TEM image, nearly hexagonal shapes for the dark spots in the images indicate that the $\mathrm{ZnO}$ nanoparticles are almost hexagonal. The estimated average particle size are 50 , $100 \mathrm{~nm}$. SEM demonstrates clearly the formation of cluster type of $\mathrm{ZnO}$ nanoparticles and change of the morphology of the nanoparticles with the $\mathrm{Nd}^{3+}$ different ions concentration. Nine absorption and four fluorescence bands have been observed in $\mathrm{ZnO}: \mathrm{Nd}^{3+}$ nanomaterials at room temperature. The energy interaction and Judd-Ofelt parameters have been computed using absorption spectrum data. The radiative properties, such as radiative transition probability, branching ratio, stimulated emission cross section were investigated using the J-O intensity parameters and fluorescence data.

\section{Acknowledgements}

The authors would like thankful to Principal, Govt. P. G. College Rudrapur and Haldwani for lab facilities and IIT Roorkee for characterization of the present work.

\section{References}

[1] Erik Gregersen, Vitalij K. Pecharsky, Encyclopedia Britannica; (Jan 17, 2019).

[2] Wang Y. S., Thomas P. J., and 'Brien P. O.: J. Phys. Chem. B, 110, 21412, (2006).

[3] Greene L., Law M., Tan D. H., Goldberger J., Yang P.: Nano Lett., 1231, (2005). 
[4] Suchea M., Christoulakis, Moschovis S., Katsarakis K., Kiriakidis N.: ZnO transparent thin films for gas sensor applications. Thin Solid Films. 515, 551, (2006).

[5] Ashour A., Kaid M. A., El-Syed N. Z., Ibrahim A. A.: Physical properties of $\mathrm{ZnO}$ thin films deposited by spray pyrolysis technique. Appl. Surf. Sci. 252, 7844-7848, (2006).

[6] Chen J. C., Tang C. T.: Preparation and application of granular $\mathrm{ZnO} / \mathrm{Al} 2 \mathrm{O} 3$ catalyst for the removal of hazardous trichloroethylene. J. Hazard. Mater. 142, 88-9, (2007).

[7] Judd B. R.: Phys. Rev., 12, 750-761, (1962).

[8] Ofelt G. S.: J. Chem. Phys., 37, 511-520, (1962).

[9] Shinde K. N.: Phosphate Phosphors for Solid-State Lighting, Springer Series in Materials Science 174, (2013).

[10] Daksh D. and Agrawal Y. K.: Rare Earth-Doped Zinc Oxide Nanostructures: A Review; American scientific publishers; Reviews in Nanoscience and Nanotechnology; Vol. 5, pp. 127, (2016).

[11] Urban J., Haram S. K., Gosavi S. W. and Kulkarni S. K.: Pramana, 65, 615, (2005).

[12] Koch U., Fojtik A., Weller H. and englein A.: Chem. Phys. Lett., 122, 507, (1985).

[13] Sharma K. Y., Pal S., GoyalP. and Bind C. U.: AIP Conference Proceedings 1728-1732 (2016).

[14] Zhang J., Deng J. S., Liu Y. S., Chen M. J., Han Q. B., Wang Y and Wang D. Y.: Preparation and photocatalytic activity of $\mathrm{Nd}$ doped $\mathrm{ZnO}$ nanoparticles, Advanced Performance Materials Volume 29 (2014).

[15] Mai M. A. Ahmed, Wael Z. Tawfik, M. A. K. Elfayoum; Tailoring the optical and physical properties of $\mathrm{La}$ doped $\mathrm{ZnO}$ nanostructured thin films, journal of alloy and compound, Volume 791, Pages 586-592 (2019).

[16] Prathibha Vasudevan, Viji Vidyadharan, Sanu Mathew Simon, Unnikrishnan N. V; Phytochemical mediated synthesis of $\mathrm{ZnO}: \mathrm{Dy}^{3+}$ nanophosphors: JuddeOfelt analysis, structural and spectroscopic properties; Journal of Science: Advanced Materials and Devices (in press -Accepted 3 May 2020).

[17] Anwar F. and Farrrukh A. M: "Synthesis, Charactrization and Photocatalytic Application of Gd Doped ZnO Nanoparticles", Asian journal of Chemistry, Vol. 27 No. 10, 3571-3574, 10 (2015).
[18] Odireleng Martin Ntwaeaborwad, Sefako J. Mofokenga, Vinod Kumarb, Robin E. Kroon; Structural, optical and photoluminescence properties of $\mathrm{Eu}^{3+}$ doped $\mathrm{ZnO}$ nanoparticles, Spectrochimica Acta Part A: Molecular and Biomolecular Spectroscopy, 42-49, 182 (2017).

[19] K. Ravichandrika, P. Kiranmayi, R. V. S. S. N. Ravikumar, Synthesis, characterization andantibacterial activity of $\mathrm{ZnO}$ nanoparticles, Int. J. Pharm. Pharm. Sci. 4 (4) 336-338 (2012).

[20] X. Liu, J. Zhang, L. Wang, T. Yang, X. Guo, S. Wu, S. Wang, 3D hierarchically porousZnO structures and their functionalization by au nanoparticles for gas sensors, J. Mater. Chem. 21 349-356 (2011).

[21] S. Husain, F. Rahman, N. Ali, P. A. Alvi, Nickel sub-lattice effects on the optical prop-erties of $\mathrm{ZnO}$ nanocrystals, $\mathrm{J}$. Optoelectron. Eng. 1 (1) 28-32 (2013).

[22] Sharma Y. K., Pal S., Goyal P. and Verma L. P.: "Fluorescence Studies of ZnO Nanomaterial with Samarium Ion" J. Chem. Eng. Chem. Res. Vol. 3, No. 11, 2016, pp. 1027-1030 (2016).

[23] Shuichi Yamagata, Yusuke Hamba, Ko Nakanishi, Shigeaki Abe, Tsukasa Akasaka, Natsumi Ushijima, Motohiro Uo, Junichiro Iida, And Fumio Watari; Introduction of Rare-EarthElement- Containing $\mathrm{ZnO}$ Nanoparticles into Orthodontic Adhesives, Nano Biomedicine 4 (1), 11-17, 2012.

[24] Omata T., Fujiwara H., Otsuka- S. Yao-Matsuo, Ono N.: Appl. Phys. A, 71609 (2000).

[25] Sharma Y. K.,. Surana S. S. L,. Dubedi R. P and Joshi V.: Spectroscopic and radiative properties of $\mathrm{Sm}^{3+}$ doped zinc fluoride borophosphate glasses; Mat. Sci. and Engg. (France) B119, 131 (2005).

[26] Sharma Y. K., Dubedi R. P., Joshi V., Karnataka K. B. and Surana S. S. L.: Absorption studies of tripositive praseodymium and neodymium doped zinc fluoride borophosphate (ZFBP) glasses; Indian J. Eng. and Mat. Sci. (India) 12, 65 (2005).

[27] Surana S. S. L., Gehlot C. L., Tandon S. P. and. Sharma Y. K: Fluorescence of $\mathrm{Sm}^{3+}, \mathrm{Eu}^{3+}, \mathrm{Tb}^{3+}, \mathrm{Ho}^{3+}$ and $\mathrm{Er}^{3+}$ doped borophosphate glasses; Can. J. Analytical Sciences and Spectroscopy (Canada) 48, 285-294 (2003). 